\title{
Recurrent Meningioma
}

National Cancer Institute

\section{Source}

National Cancer Institute. Recurrent Meningioma. NCI Thesaurus. Code C5312.

The reemergence of a meningioma after a period of remission. 